\title{
Application of response surface methodology for the removal of 4- nitroaniline in aqueous solution using activated carbon prepared from peanut shells and avocado seed
}

\author{
Collins Ngoe Elangwe ${ }^{\text {a }}$, Aurelien Bopda ${ }^{\text {a }}$, Donald Raoul Tchuifon Tchuifon ${ }^{\text {a }}$, Nche George \\ Ndifor-Angwafora,* a \\ ${ }^{a}$ Research unit of Noxious Chemistry and Environmental Engineering, University of Dschang, \\ P.O. Box 67, Dschang, Cameroon
}

\begin{abstract}
In this study, response surface methodology (RSM) was employed to optimize the adsorption of 4-nitroaniline (4-NA) from aqueous solution onto activated carbons obtained from peanut shells (PNAC) and avocado seed (ASAC).The aim was to evaluate the adsorption capacity of PNAC and ASAC for the retention of 4-NA. The samples were activated with $0.6 \mathrm{M} \mathrm{KOH}$ and were characterized using FTIR, XRD techniques. Different physicochemical properties such as moisture content, $\mathrm{pH}, \mathrm{pHpzc}$ and iodine number were also determined. Response surface methodology was used to study the interactive effect and to optimize the operational parameters on the adsorption capacity of 4-NA onto PNAC and ASAC. It was shown that a second order polynomial regression model properly interprets the experimental data with correlation coefficients of determination (R2) values of $97.17 \%$ and $95.68 \%$ for 4-NA adsorption on PNAC and ASAC respectively. Results also showed that the optimum conditions for the adsorption of 4-NA from aqueous solution onto PNAC and ASAC were as follows: optimum initial 4-NA concentration of $50 \mathrm{mg} / \mathrm{L}, \mathrm{pH}$ of 3 and contact time of 49.05 minutes onto PNAC and 65.5 minutes onto ASAC were obtained which resulted to an optimum adsorption capacity of $3.10 \mathrm{mg} / \mathrm{g}$ and $2.42 \mathrm{mg} / \mathrm{g}$ of 4-NA onto PNAC and ASAC respectively. The results obtained showed that peanut shell activated carbon exhibited a better performance than avocado seed activated carbon for the removal of 4-NA from aqueous media.
\end{abstract}

*Corresponding author. Tel.: +237 677504573 E-mail address : nchegeorged4@yahoo.com

Keywords: Activated Carbon; Adsorption; Central Composite design; 4-NA, RSM 


\section{Introduction}

Industrial expansion, rapid urbanization, and generation of wastes from industrial, pharmaceutical and agricultural sources have rendered many water sources unwholesome and hazardous to man and the environment in most countries including Cameroon (Alemagi et al., 2006). Organic compounds such as nitroaniline compounds are extensively used in textile, plastic, food, leather, paper, cosmetics andpharmaceutical industries as precursor in the manufacture of several organic compounds and materials such as phenylenediamine, azo dyes, antioxidants, fuel additives, corrosion inhibitors, pesticides, antiseptic agents, and medicines for poultry as well as in the synthesis of pharmaceuticals (Gerald, 2005). Effluents from such industries are sources of pollution and disposal of such waste requires much attention.4nitroaniline (4-NA) is extremely harmful to aquatic life and human healthdue to its hematoxicity, splenotoxicity and nephrotoxicity, meaning that it damages all kind of cells (Bhunia et al., 2003; Mackinson et al., 1981). Moreover, the presence of a nitro group in the aromatic ring of 4NA makes it resistant to chemical and biological oxidative degradation, while its anaerobic degradation produces nitroso and hydroxylamines compounds that are carcinogenic (Oturan et al., 2000). There is a need to remove 4-NA from waste effluents generated from these industries before being discharged into rivers or public sewage networks. Various wastewater treatment technologies have been proposed for the removal of 4-NA and other organic contaminants from waste waters; these include advanced oxidation processes, solvent extraction and biodegradation, electrochemical oxidation and biochemical treatment (Mckay et al., 1998).

Problems associated with the above mentioned methods include the high cost, low efficiency and the generation of toxic and secondary products (Ferro et al., 2007). Therefore, new cost effective technologies for the removal of 4-NA are crucial. Adsorption has been chosen as one of the most widely acceptable effective techniques to remove 4-NA and other organic pollutants at higher concentration due to its relatively simple design, cost effectiveness, ease of operation and simple adsorbent regeneration (Dhiraj et al., 2008).

Designing of experiment and the standardization of variables affecting the system is very critical in optimization process. Generally, this optimization is carried out using the classical (mechanistic) one factor at a time method. This method is easily applied, but time and chemicals are consumed in large amounts (Narayana et al., 2011). Moreover classical method neglects the interaction effects of process variables which can have large impact on the results (Veronica et al., 1999). Hence, in the present study statistical approach such as response surface methodology (RSM) was adopted to study the correlation among the process variables affecting the process and to optimize the process variables (Myers et al., 2016) to give higher 4-NA removal. The main objective of this study was to evaluate the adsorption capacity of avocado seed activated carbon and peanut shell activated carbon in the retention of 4NA from aqueous solution.

\section{Materials and Methods}

\subsection{Preparation of adsorbents and adsorbate}

In this present study, the agricultural wastes we used are avocado pear seed and peanut shells. These wastes were obtained from Fokoue village, Menoua division in the West region 
of Cameroon. The collected avocado seeds and the peanut shells were washed using distilled water to remove dirt before it was dried. The dried avocado seeds and peanut shells were crushed and impregnatedwith $\mathrm{KOH}$ solution. $20 \mathrm{~g}$ of the biomass was stirred with $100 \mathrm{~mL}$ of $0.6 \mathrm{M}$ potassiumhydroxide solution for 1 hour at room temperature. The biomasses were later dried in an oven at $55{ }^{\circ} \mathrm{C}$ for 24 hours. The treated biomasses were later carbonized at $450{ }^{\circ} \mathrm{C}$ for 3 hours. The carbonized products obtained were washed several times with distilled water to neutralize $\mathrm{pH}$ and dried in the oven at $55{ }^{\circ} \mathrm{C}$ for 24 hours. The samples were later crushed into fine particle size and sieve in order to obtain fine particle size below $100 \mu \mathrm{m}$. The different activated carbons obtained were abbreviated as PNAC and ASAC for peanut shells activated carbon and avocado seed activated carbon respectively. 4-nitroaniline was used as an adsorbate for this study. A stock solution of 4-nitroaniline $(500 \mathrm{mg} / \mathrm{L})$ was prepared by dissolving $125 \mathrm{mg}$ of the adsorbate in $250 \mathrm{~mL}$ of distilled water, and then diluted to obtain the desired concentration. The solution $\mathrm{pH}$ was adjusted with $0.1 \mathrm{M} \mathrm{HCl}$ or $0.1 \mathrm{M} \mathrm{NaOH}$, and $\mathrm{pH}$ measurement was achieved using the $\mathrm{pH}$ meter.

\subsection{Methods of characterization of activated carbons}

\subsubsection{Fourier Transform-IR Spectroscopy}

The different activated carbons were characterized by Fourier Transform Infrared (FTIR) spectrophotometer. This technique helps in the identification of chemical functional groups on the surface (Kifuani et al., 2012). It is an analytic technique with three principal advantages as non-destructive, fast, and uses small amount of the samples.

\subsubsection{Powder X-ray diffraction (XRD) study}

Crystalline and amorphous structure of the precursors (biomasses) and activated carbons were determined by X-ray diffraction analysis using a STOE Stadi-p X-ray powder diffractometer (STOE \& Cie GmbH, Darmstadt, Germany), with $\mathrm{Cu}$ Kal radiation (40 KV, 30 $\mathrm{mA}$ and $\lambda=1.54056 \AA$ ). The diffraction angle was varied from 0 to 70 degree. The X-ray diffraction patterns were collected with scan rate of $5^{\circ} \mathrm{C} / \mathrm{min}$.

\subsection{3. $\mathrm{pH}$ of the activated carbons}

The $\mathrm{pH}$ of the activated carbons was determined by putting $50 \mathrm{~mL}$ of distilled water and $0.5 \mathrm{~g}$ of each of the carbons in different washed bottles. The mixtures were agitatedfor 24 hours at room temperature. After which, the mixtures were filtered and the $\mathrm{pH}$ of the filtrates was measured (Tchuifon et al., 2014).

\subsubsection{Iodine number}

The iodine number was measured using the procedure established by the American society for testing and materials (ASTM). It is defined as the quantity of iodine adsorbed in milligram per gram of powder activated carbon. It measures the micropore diameter less than $2 \mathrm{~nm}$ on the surface of the activated carbon. In $250 \mathrm{~mL}$ volumetric flask, $0.02 \mathrm{~N} \mathrm{I}_{2}$ solution and $0.05 \mathrm{~N}$ KI solution were introduced in the flask. After which $0.1 \mathrm{~g}$ of the activated carbons were measured and introduced in washed bottles followed by the addition of $30 \mathrm{~mL}$ of $0.002 \mathrm{~N} \mathrm{I}_{2}$ solution. The mixtures were agitated for 3 hours and later filtered. After filtration, $10 \mathrm{~mL}$ of the filtrate was 
titrated with $0.005 \mathrm{~N} \mathrm{Na} 2 \mathrm{~S}_{2} \mathrm{O}_{3} .5 \mathrm{H} 2 \mathrm{O}$ solution using starch as indicator (Tchuifon et al., 2014). The quantity adsorbed (iodine number) was determined as follows:

$$
\mathrm{Q}_{\mathrm{e}}=\frac{\mathrm{Co}-\mathrm{Ce}}{m} \mathrm{~V}
$$

where $\mathrm{m}$, mass of the activated carbon, $\mathrm{C}_{\mathrm{o}}$ is the initial concentration of iodine, $\mathrm{C}_{\mathrm{e}}$ is the concentration of iodine at time $\mathrm{t}, \mathrm{V}$ is the volume of iodine solution and Qe is iodine number

\subsubsection{Determination of the point of zero charge (pHpzc)}

The pHpzc is an important characteristic for any activated carbon as it indicates the acidity/basicity of the adsorbent and the net surface charge of the carbon in solution (i.e. the $\mathrm{pH}$ of the solution when the net surface charge equals zero). When the $\mathrm{pHpzc}>\mathrm{pH}$ of the solution, the net surface charge of the activated carbon is positively charged, and when the pHpzc < $\mathrm{pH}$ of the solution, the net surface charge of the activated carbon is negatively charged [14].To measure the pHpzc, the $\mathrm{pH}$ of the solution is maintained by using $0.1 \mathrm{~N} \mathrm{HCl}$ and $0.1 \mathrm{~N}$ $\mathrm{NaOH}$ solutions. Mixtures of $0.1 \mathrm{~g}$ of activated carbon samples and $50 \mathrm{~mL}$ of $0.01 \mathrm{~mol} \mathrm{L-1NaCl}$ solutions of initial $\mathrm{pH}$ values varying from 2 to 10 were agitated for 24 hours at ambient temperature (Lopes-Ramon et al., 1999). The change in $\mathrm{pH}$ was measuredand plotted against the initial $\mathrm{pH}$. The $\mathrm{pH}$ PzC was equal to the value for which change in $\mathrm{pH}$ cuts the axis of initial $\mathrm{pH}$.

\subsubsection{The moisture content}

The moistue content is the amount of water present in the adsorbent compared to the dry mass of the adsorbent. In a weight beaker, $0.1 \mathrm{~g}$ of the activated carbon was introduced in it. After which, the beakers containing the activated carbons were put in an oven at 1100C for 1 hour. The beakers were later allowed to cool, after which they were weighed and the new mass was recorded. The percentage of mass obtained from the mass difference gave us the moisture content of the materials (Tchuifon et al., 2014).

$$
\% \text { Moisture content }=\frac{m i-m f}{m i} 100
$$

where $\mathrm{m}_{\mathrm{i}}$, the initial mass, $\mathrm{m}_{\mathrm{f}}$ is the final mass of the carbon.

\subsection{Batch adsorption mode}

The effects of initial 4-NA concentration, $\mathrm{pH}$, and contact time were studied.The adsorbent dosage was $25 \mathrm{mg}$. Different concentrations of 4-NA solutions of $50 \mathrm{~mL}$ ranging from $20-50 \mathrm{mg} / \mathrm{L}$ were transferred separately to different washed bottles. $25 \mathrm{mg}$ of the adsorbents were added to the flasks and the $\mathrm{pH}$ was adjusted by using $0.1 \mathrm{M} \mathrm{NaOH}$ or $0.1 \mathrm{M} \mathrm{HCl}$ solution. The experiment was conducted at $\mathrm{pH}$ range of 3-9. Then, the effect of the treatment time was studied by varying the contact time between 10-120 minutes at a constant agitation speed (150 trs/min). All the adsorption experiments were carried out at room temperature. All samples were analyzed using UV-Vis spectrophotometer at maximum wavelength of $298 \mathrm{~nm}$, to determine the final concentration of the solution. The quantity (Qe) of 4-nitroaniline adsorbed from the solution is calculated as; 


$$
\mathrm{Qe}=\frac{C o-C e}{m} V
$$

where $C_{o}$ and $C_{e}$ are the initial and equilibrium concentrations of the 4-nitroaniline in solution (i $\mathrm{n} \mathrm{mg/L}$ ), $\mathrm{V}$ is the volume of the solution, and $\mathrm{m}$ is the mass of the adsorbent.

\subsection{Experimental design}

The response surface method through central composite was employed to identify the relationship between a set of controllable experimental factors and observed results. The optimization process involvesthree major steps; performing the statistically designed experiments, estimating the coefficients in a mathematical model and predicting the response and checking the adequacy of the model (Annadurai et al., 2000). The table 1 shows the experimental range for each factor used and defined in three level (low, average, and high) coded as $(-1,0,+1)$.

Table 1. Experimental values and coded levels of the independent variables

\begin{tabular}{llll}
\hline Independent & & Levels & \\
variables & $\mathbf{- 1}$ & $\mathbf{0}$ & $\mathbf{+ 1}$ \\
\hline $\begin{array}{l}\text { Initial } \\
\text { Concentration(mg/L }\end{array}$ & 20 & 35 & 70 \\
pH & 3 & & \\
Contact time(min) & 10 & 65 & 9 \\
\hline
\end{tabular}

The central composite designed with three factors, two levels that is low and high and with 16 experimental runs was used for the optimization process. This design consists of two replicated center points and the set of points that defined the region of interest. The three independent variables were coded according to the following equation (4):

$$
\mathrm{X}_{\mathrm{i}}=\frac{X i-X o}{\Delta X}
$$

where $\mathrm{x}_{\mathrm{i}}$ is dimensional value of an independent variable, $\mathrm{Xi}$ the actual value of an independent variable $\mathrm{i}$, Xo the actual value of the independent variable at the center point and is the step change of Xi corresponding to a unit variation of the dimensionless value (Ravikumar et al., 2007). The mathematical relationship of the response (quantity adsorbed) and the independent variables was modeled by a second order polynomial function as follows:

$Y=\beta_{0}+\beta_{1} X_{1}+\beta_{2} X_{2}+\beta_{3} X_{3}+\beta_{12} X_{1} X_{2}+\beta_{23} X_{2} X_{3}+\beta_{13} X_{1} X_{3}+B_{11} X_{12} \beta_{22} X_{2}{ }^{2}+\beta_{33} X_{3}{ }^{2}+\varepsilon$

where $Y$ is the predicted response, $\beta_{0}$, is the intercept, $\beta_{1}, \beta_{2}, \beta_{3}$ are linear coefficient, $\beta_{12}, \beta_{23}$, $\beta_{13}$ are the interaction coefficients, and $\beta_{11}, \beta_{22}$ and $\beta_{33}$, are the squared coefficients, $X_{1}$, $X_{2}$ and $X_{3}$ are the independent variables and $\epsilon$ is the noise or error. The statistical analysis of the data was done by using Statgraphics plus 5.0 software in order to determine the best model for the removal of 4-NA from aqueous solution. An analysis of variance by calculating F-value was employed. ANOVA was used to recognize the relationship between the response and the independent variables. The p-value was used as an indicator to verify the significance of each term. 
If the p-value was less than 0.05 indicates that the factor influences the experiment (Montgomery, 2017). The indicator for the fitness of the second order polynomial model was evaluated by coefficient of determination $\left(\mathrm{R}^{2}\right)$.

\section{Results and discussion}

\subsection{Characterization of Adsorbents}

\subsubsection{FT- IR Spectra}

The precursors and the activated carbons were characterized by IR spectroscopy in order to identify thevarious functional groups present on their surfaces and to know if some modifications of functional groups have been made during the preparation of the activated carbons. The IRspectra of the peanut shell biomass (PSB) and avocado seed biomass (ASB) and the activated carbons (PNAC andASAC) are represented in the Fig1 and Fig2.

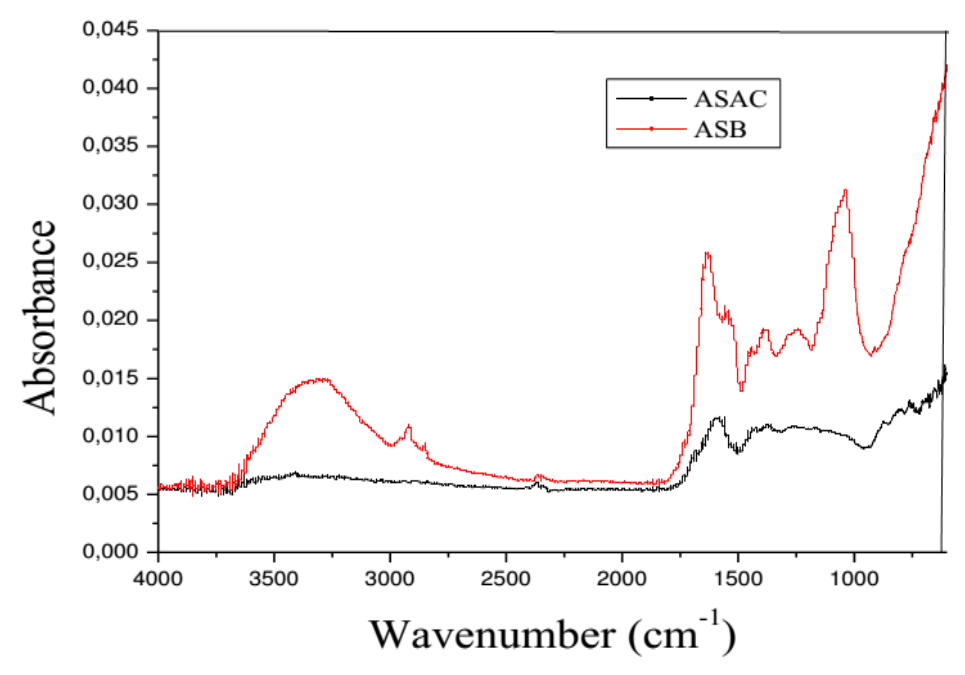

Fig. 1. Superposed IR spectra of avocado seed biomass and avocado seed activated carbon (ASAC).

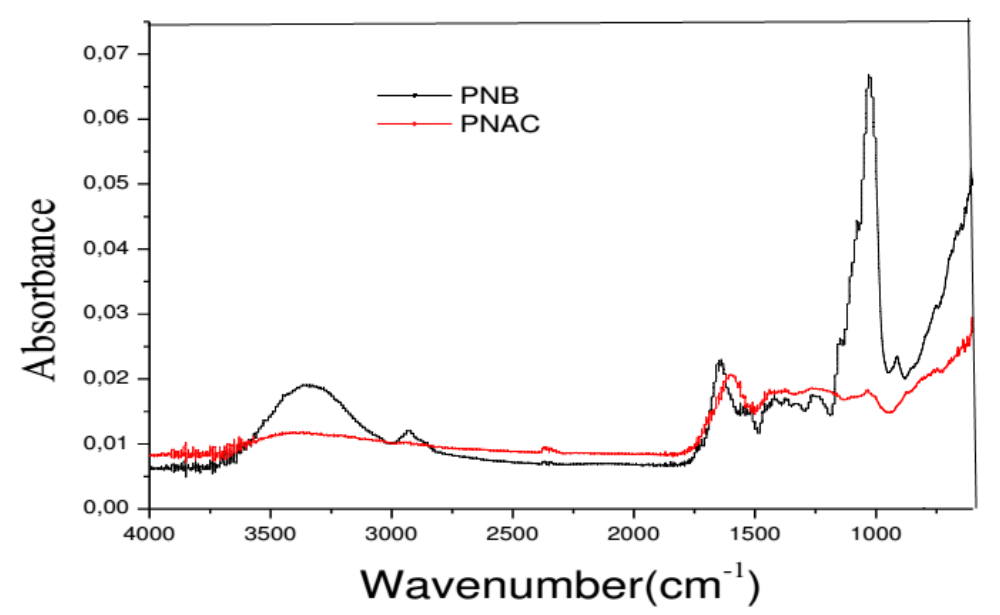

Fig. 2. Superposed IR spectra of peanut shells biomass and peanut shells activated carbon 
In Figs 1 and 2, we observe that the absorption band (3500-3200 cm-1) which characterizes of $\mathrm{OH}$ functional group present in both PNB and ASB, is absent in ASAC and a weak band in PNAC. The absence or reduction of $\mathrm{OH}$ functional group in the activated carbons could be as a result of carbonization which is the cause of the elimination of atoms of $\mathrm{C}$, $\mathrm{H}$, and $\mathrm{O}$ in the form of $\mathrm{CO}_{2}, \mathrm{H}_{2} \mathrm{O}$ and aldehyde (Ndi \& Ketcha, 2013).. Also the disappearance of hydrogen bond shows that the sodium hydroxide was acting as a dehydrating agent (SuarezGarcia et al., 2002).. The adsorption band at $2919 \mathrm{~cm}-1$ assigned to the vibration of C-H bond $(\mathrm{sp} 3 \mathrm{C}-\mathrm{H})$ has also disappeared in the activated carbons, indicating that activation breaks or remove significant parts of the $\mathrm{C}-\mathrm{H}$ bonds in aliphatic and aromatic species (Yagmur et al., 2008). The adsorption band at $1000 \mathrm{~cm}-1$ for $\mathrm{C}-\mathrm{O}$ vibration has disappeared in ASAC and of weak intensity in PNAC. The disappearance or diminution of the peak intensity (about $1000 \mathrm{c}-1$ ) of ASAC and PSAC is due to the hydrolysis of the $\mathrm{C}-\mathrm{O}$ bonds present in esters. The variation of the intensity of the peaks of PNB and ASB around 1250 and $1000 \mathrm{~cm}-1$ is also noticed in the Figs 1 and 2. The high peak intensity $(1239 \mathrm{~cm}-1)$ of PNB is due to the presence of the conjugated CO bond (that is $\mathrm{O}=\mathrm{C}-\mathrm{O}$ or $\mathrm{C}=\mathrm{C}-\mathrm{O}$ ). The low peak intensity of ASB is due to the presence of $\mathrm{C}-\mathrm{O}$ bond in esters. We also notice around $900-700 \mathrm{~cm}-1$ of the PNB spectra the presence of $\mathrm{C}-\mathrm{H}$ bond of the aromatic system.

\subsubsection{X-ray diffraction (XRD) analysis of biomasses and activated carbons}

The results of powder X-ray diffraction obtained for peanut shell biomass (PNB), avocado seed biomass (ASB) and the activated carbons (PNAC and ASAC) are presented in figure 8. The existence of broad peaks indicates that the materials are amorphous (Omri \& Benzia, 2012). As for the avocado seed biomass, there is the appearance of a sharp peak at $2 \theta=26.5^{\circ}$ and small sharp peaks at $2 \theta=35.1,55.5$ and 600 . This signifies an increasing regularity of crystalline structure, which will result in a better layer alignment (Kumar, 2013). The absence of a sharp peak reveals that the activated carbon prepared from ABS is mainly amorphous (Omri \& Benzia, 2012). The disappearance of the sharp peaks is mainly due to the removal of lignin and the breakdown of the ester bonds between lignin and other components during $\mathrm{KOH}$ pretreatment and carbonization of the biomass. The amorphous nature of our activated carbon is an advantageous property for well-defined adsorbent. However, the small sharp peaks presented by the X-ray graph of PNAC ( $2 \theta=25.30$ and 28.0) indicates a very low crystallinity on this activated carbon resulting from better layer alignment (Kumar, 2013). The sharp peaks are due to the presence of potassium carbonate and potassium oxide (Hui \& Zaini, 2015; Lillo Ródenas et al., 2003). 

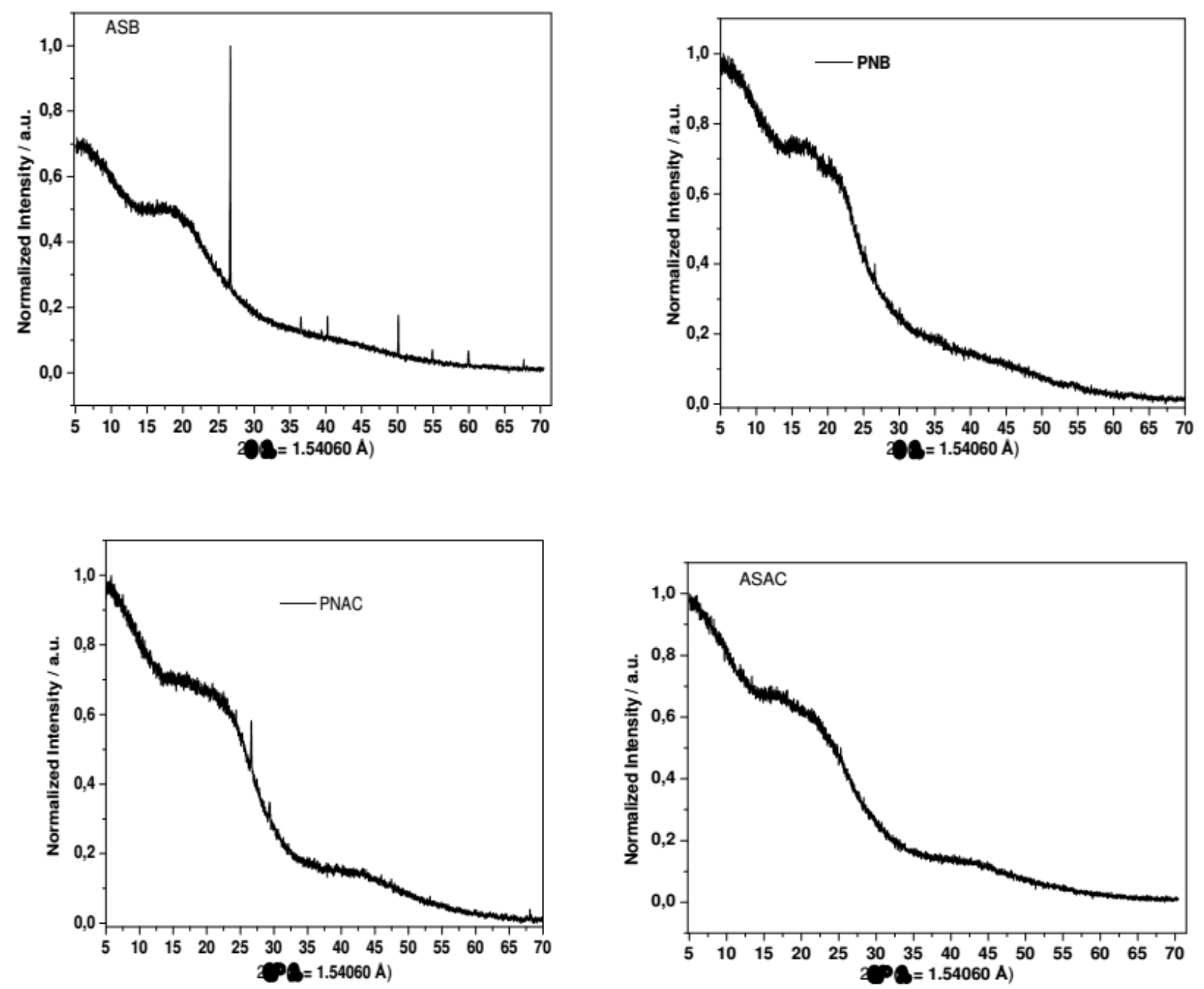

Fig. 3. Powder XRD of ASB, ASAC, PNB and PNAC

Table 2. Physicochemical characterization of activated carbons

\begin{tabular}{lll}
\hline Activated carbon & PNAC & ASAC \\
\hline Moisture content $(\%)$ & 4.1 & 5.0 \\
pH & 7.6 & 8.9 \\
pHpzc & 7.2 & 7.6 \\
Iodine number $(\mathrm{mg} / \mathrm{g})$ & 698.94 & 624.79 \\
\hline
\end{tabular}

\subsection{Experimental Design}

In order to study the combined effect of the parameters, the experiments were done for different combinations of the parameters using statistically designed experiments.. In the present investigation, adsorption of 4-NA is optimized by Central Composite design method. The regression equation obtained after analysis of variance gives the level of adsorption of 4-NA as a function of different 4-NA concentration, $\mathrm{pH}$ and contact time. All terms regardless of their 
significance are included in equations 6 and 7. The experimental results and the predicted values for the quantity of 4-NA absorbed onto PNAC and ASAC are presented in table 3.

Table 3. Experimental and the predicted values of the adsorption capacity of the adsorbents.

\begin{tabular}{llllllll}
\hline Run & $\begin{array}{l}\text { Initial } \\
\text { concentration } \\
(\mathrm{mg} / \mathrm{L})\end{array}$ & $\mathrm{pH}$ & $\begin{array}{l}\text { Contact } \\
\text { time } \\
(\text { minute })\end{array}$ & $\begin{array}{l}\mathrm{Y}_{1} \\
\text { Experimental } \\
(\mathrm{mg} / \mathrm{L})\end{array}$ & $\begin{array}{l}\mathrm{Y}_{1} \\
\text { Predicted } \\
(\mathrm{mg} / \mathrm{g})\end{array}$ & $\begin{array}{l}\mathrm{Y}_{2} \\
\text { Experimental } \\
(\mathrm{mg} / \mathrm{L}\end{array}$ & $\begin{array}{l}\mathrm{Y}_{2} \\
\text { Predicted } \\
(\mathrm{mg} / \mathrm{g})\end{array}$ \\
& $\mathrm{A}$ & $\mathrm{B}$ & $\mathrm{C}$ & & & & \\
& & & & & & & \\
$\mathbf{1}$ & -1 & 0 & 0 & 0,3076 & 0,6169 & 0,4390 & 0,7113 \\
$\mathbf{2}$ & -1 & +1 & +1 & 0,3453 & 0,1866 & 0,3012 & 0,091 \\
$\mathbf{3}$ & 0 & 0 & 0 & 1,0109 & 0,7560 & 1,0769 & 0,9305 \\
$\mathbf{4}$ & 0 & +1 & 0 & 0,4102 & 0,8164 & 0,4019 & 0,8651 \\
$\mathbf{5}$ & +1 & -1 & +1 & 2,5824 & 2,6540 & 2,0054 & 2,0892 \\
$\mathbf{6}$ & 0 & 0 & +1 & 0,1538 & 0,2958 & 0,0879 & 0,4951 \\
$\mathbf{7}$ & -1 & -1 & -1 & 2,3456 & 2,3336 & 1,4065 & 1,5578 \\
$\mathbf{8}$ & +1 & 0 & 0 & 1,2967 & 1,2423 & 1,4505 & 1,3262 \\
$\mathbf{9}$ & 0 & -1 & 0 & 2,8131 & 2,6619 & 2,3736 & 2,0584 \\
$\mathbf{1 0}$ & 0 & 0 & -1 & 0,3456 & 0,4586 & 0,9237 & 0,6644 \\
$\mathbf{1 1}$ & -1 & +1 & -1 & 0,4813 & 0,3459 & 0,5710 & 0,4502 \\
$\mathbf{1 2}$ & +1 & +1 & +1 & 1,0023 & 0,9506 & 0,9985 & 0,8102 \\
$\mathbf{1 3}$ & +1 & -1 & -1 & 2,7252 & 2,8202 & 1,8958 & 2,0688 \\
$\mathbf{1 4}$ & -1 & -1 & +1 & 2,0219 & 2,0187 & 1,5604 & 1,4676 \\
$\mathbf{1 5}$ & 0 & 0 & 0 & 1,0109 & 0,7560 & 1,0802 & 0,9305 \\
$\mathbf{1 6}$ & +1 & +1 & -1 & 1,0219 & 0,9614 & 1,0026 & 1,0585 \\
\hline
\end{tabular}

$\mathrm{Y}_{1}=$ adsorption capacity of PNAC; $\mathrm{Y}_{2}=$ adsorption capacity of ASAC

\subsubsection{Regression equation}

The full quadratic second order polynomial equation was fitted to the data appropriately and the equations were presented as follows (Ravikumar et al., 2005).

$\mathrm{Y}_{1}=6.66-0.040 \mathrm{~A}-1.65 \mathrm{~B}+0.011 \mathrm{C}+0.007 \mathrm{~A}^{2}+0.00071 \mathrm{AB}+0.00004 \mathrm{AC}+0.1092 \mathrm{~B}^{2}+0.0002 \mathrm{BC}-$

$$
0.0001 C^{2}
$$

$\mathrm{Y}_{2}=3.65-0.012 \mathrm{~A}-0.899 \mathrm{~B}+0.0148 \mathrm{C}+0.00039 \mathrm{~A}^{2}+0.00054 \mathrm{AB}+0.00003 \mathrm{AC}+0.059 \mathrm{~B}^{2}+$

$$
0.0004 \mathrm{BC}-0.0001 \mathrm{C}^{2}
$$

The table 3 confirms that the predicted data of the response from the empirical model is in good agreement with the experimentally obtained data.

\subsubsection{Analysis of variance (ANOVA) Test}

ANOVA test is performed to study the influence of all factors on quantity adsorbed. Statistical significance of the model equation and model terms was evaluated by F-test and ANOVA (Montgomery, 2017). 
Table 4. ANOVA for response surface quadratic model for (a) PNAC (b) ASAC

(a) PNAC

\begin{tabular}{lllllll}
\hline Source & $\begin{array}{l}\text { Sum of } \\
\text { Square }\end{array}$ & Df & $\begin{array}{l}\text { Mean } \\
\text { Square }\end{array}$ & $\begin{array}{l}\text { F- } \\
\text { Value }\end{array}$ & P-Value & Remark \\
\hline A:CONCENTRATION & 0.977639 & 1 & 0.977639 & 11.42 & 0.0149 & Significant \\
B:pH & 8.51439 & 1 & 8.51439 & 99.48 & 0.0001 & Significant \\
C:TIME & 0.0662602 & 1 & 0.0662602 & 0.77 & 0.4128 & \\
AA & 0.079449 & 1 & 0.0794499 & 0.93 & 0.3725 & \\
AB & 0.00829698 & 1 & 0.00829698 & 0.10 & 0.7661 & \\
AC & 0.011041 & 1 & 0.011041 & 0.13 & 0.7318 & \\
BB & 2.54802 & 1 & 2.54802 & 29.77 & 0.0016 & Significant \\
BC & 0.012085 & 1 & 0.012085 & 0.14 & 0.7200 & \\
CC & 0.378371 & 1 & 0.378371 & 4.42 & 0.0802 & \\
Total error & 0.513536 & 6 & 0.0855893 & & & \\
\hline $\mathbf{R}^{2}=\mathbf{0 . 9 7 1 7 9 7}$ & & & & & &
\end{tabular}

(b) ASAC

\begin{tabular}{lllllll}
\hline Source & $\begin{array}{l}\text { Sum of } \\
\text { Square }\end{array}$ & Df & $\begin{array}{l}\text { Mean } \\
\text { Square }\end{array}$ & $\begin{array}{l}\text { F- } \\
\text { Value }\end{array}$ & $\begin{array}{l}\text { P- } \\
\text { Value }\end{array}$ & Remark \\
\hline A:CONCENTRATION & 0.945355 & 1 & 0.945355 & 6.70 & 0.0413 & Significant \\
B:pH & 3.55984 & 1 & 3.55984 & 25.25 & 0.0024 & Significant \\
C:TIME & 0.071625 & 1 & 0.071625 & 0.5 & 0.5028 & \\
AA & 0.0205061 & 1 & 0.0205061 & 0.15 & 0.7161 & \\
AB & 0.00473306 & 1 & 0.00473306 & 0.003 & 0.8607 & \\
AC & 0.00612438 & 1 & 0.00612438 & 0.004 & 0.8418 & \\
BB & 0.74397 & 1 & 0.74397 & 5.28 & 0.0614 & \\
BC & 0.0360846 & 1 & 0.0360846 & 0.26 & 0.6310 & \\
CC & 0.32437 & 1 & 0.32437 & 2.30 & 0.1801 & \\
Total error & 0.846046 & 6 & 0.141008 & & & \\
\hline
\end{tabular}

$\mathbf{R}^{2}=\mathbf{0 . 9 5 6 8}$

As shown in table 4, the ANOVA analysis shows that the significance of the regression coefficients were analyzed using the p-test and f-test. The p-values are used to check the consequences and patterns of interactions among the variables. In general, the larger the magnitude of the $\mathrm{f}$-value and smaller the $\mathrm{p}$ value $(\mathrm{p}<0.05)$, the greater is the significance of the corresponding coefficient term (Khuri, 2017). From the f-value and p-value results show that the linear terms of $\mathrm{pH}$ and initial 4-NA concentration were significant $(\mathrm{p}<0.05)$, while the quadratic effect of $\mathrm{pH}$ was also significant $(\mathrm{P}<0.05)$. A high $\mathrm{R}^{2}$ (coefficient of determination) value, close to 1 , is desirable and ensures a satisfactory adjustment of the quadratic model to the experimental data (Sadri et al.,2010). According to the ANOVA results, the model presents high $\mathrm{R}^{2}$-value of $97.17 \%$ for adsorption of 4-NA onto PNAC and $95.68 \%$ onto ASAC indicates 
that the accuracy of the polynomial model was good. PNAC shows the best quadratic model with higher $\mathrm{R}^{2}$ value.

\subsubsection{Response surface and contour plotting for evaluation of operational parameters}

To evaluate the relationships and interactions of parameters, the three dimensional response surface and contour plot obtained from second polynomial equations are shown in Figs 4 and 5. The optimum values of the variables were obtained as the response is maximized using the RSM technique. The best response range can be obtained by analyzing the response surface plots. The combined effect of initial concentration of 4-NA and $\mathrm{pH}$ of the solution on adsorption of 4-NA at constant contact time is shown in Fig 4. It reveals that the uptake of 4NAincreased with increasing the initial concentration of 4-NA and a decreased $\mathrm{pH}$. The increased in adsorption capacity as initial concentration increases is due to the fact that sufficient adsorption sites with the maximum adsorption potential are available on the adsorbent surface (Azeez \& Adekola, 2016). The adsorption of 4-NA onto PNAC and ASAC was found to be a maximum in the acidic medium. As the $\mathrm{pH}$ of the adsorption solution was lowered, the positive charges on the surface increased. The higher uptake of 4-NA at low $\mathrm{pH}$ could probably be due to the electrostatic attraction between the adsorbent surface and the lone pair electrons on the amino groups of 4-NA (Azeez \& Adekola, 2016).

The interactive effect of initial concentration and contact time at constant $\mathrm{pH}$ is shown in Fig 5. It can be observed in Fig 4 that at the initial stage, the adsorption capacity was increased with time up to 49 minutes and 65.5 minutes for PNAC and ASAC respectively. Beyond these times, the adsorption capacity began to decrease. The sharp rise in the adsorption of 4-NA at the initial stage is an indication that at the beginning there are several available sites to be occupied, their number decreases with time until eventually a plateau is reached indicating the establishment of adsorption-desorption equilibrium (Azeez\& Adekola, 2016).
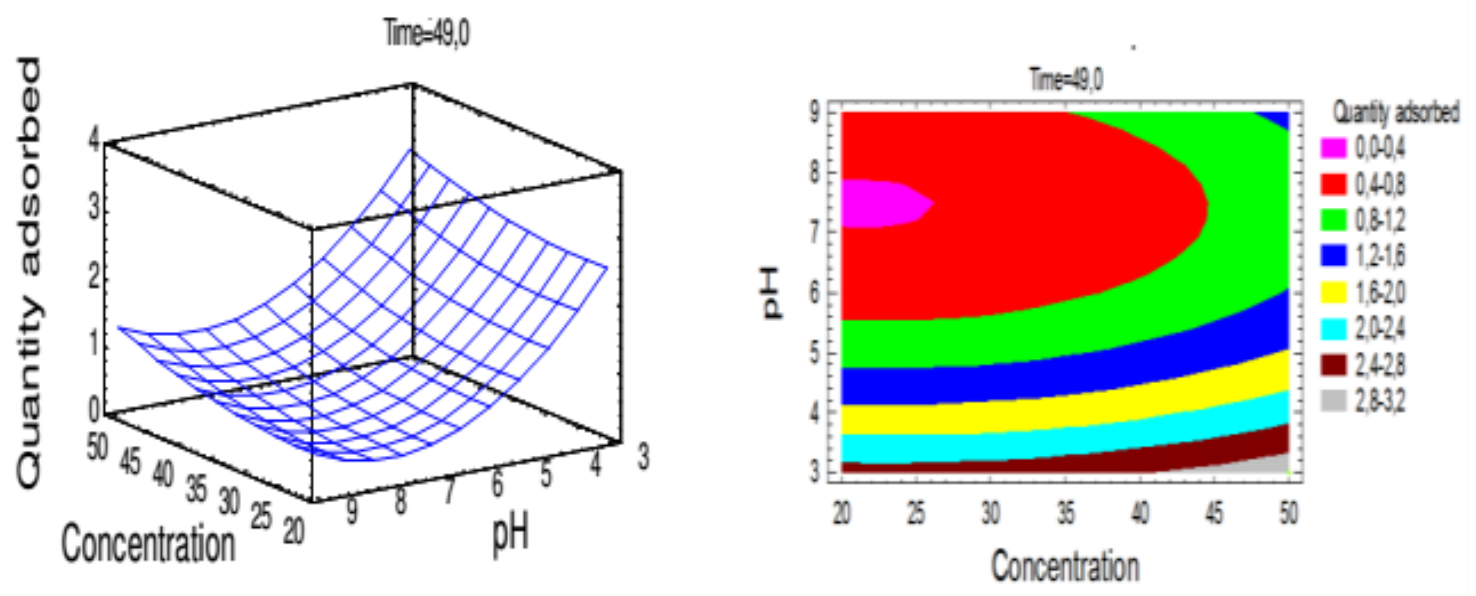

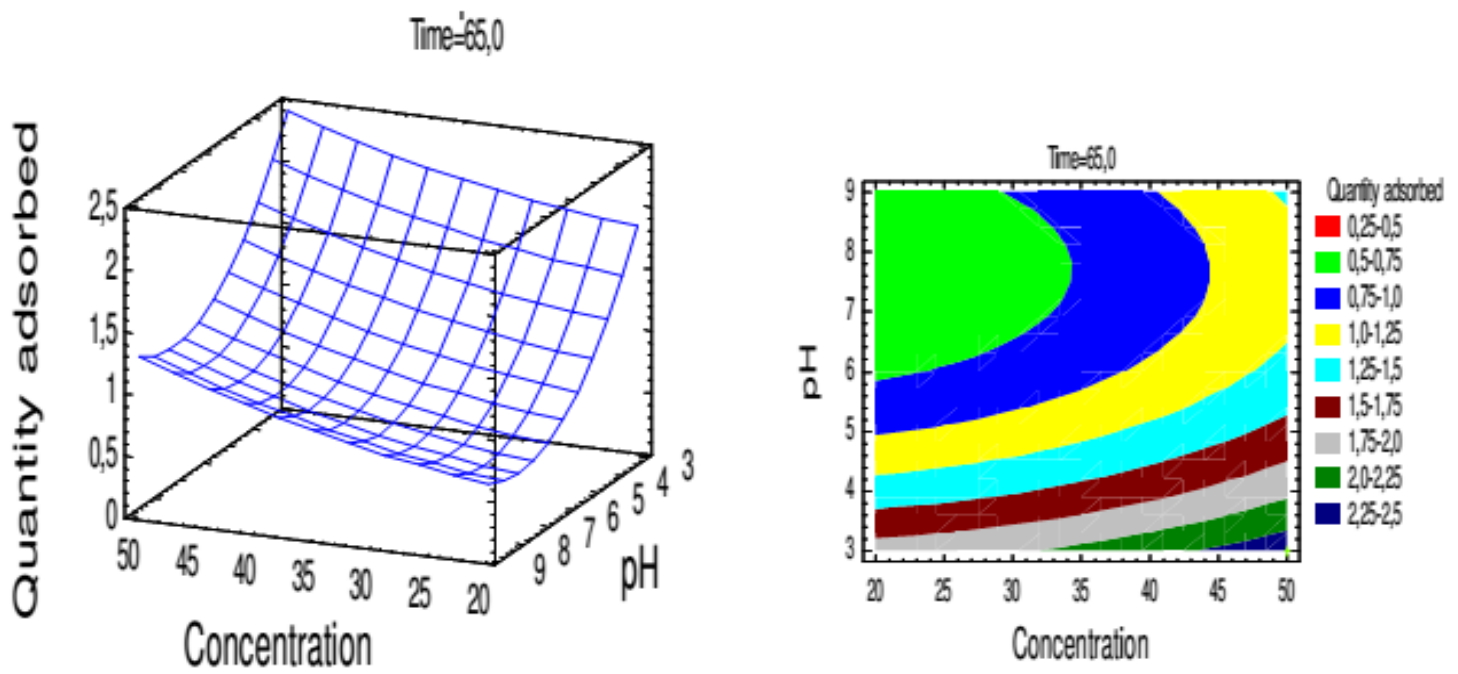

Fig.4. 3D response surface graph (A and $\mathrm{B}$ ) and contour plot $(\mathrm{C}$ and $\mathrm{D})$ of quantity adsorbed versus initial concentration $(\mathrm{mg} / \mathrm{L})$ and $\mathrm{pH}$ onto PNAC and $\mathrm{ASAC}$ at constant contact time
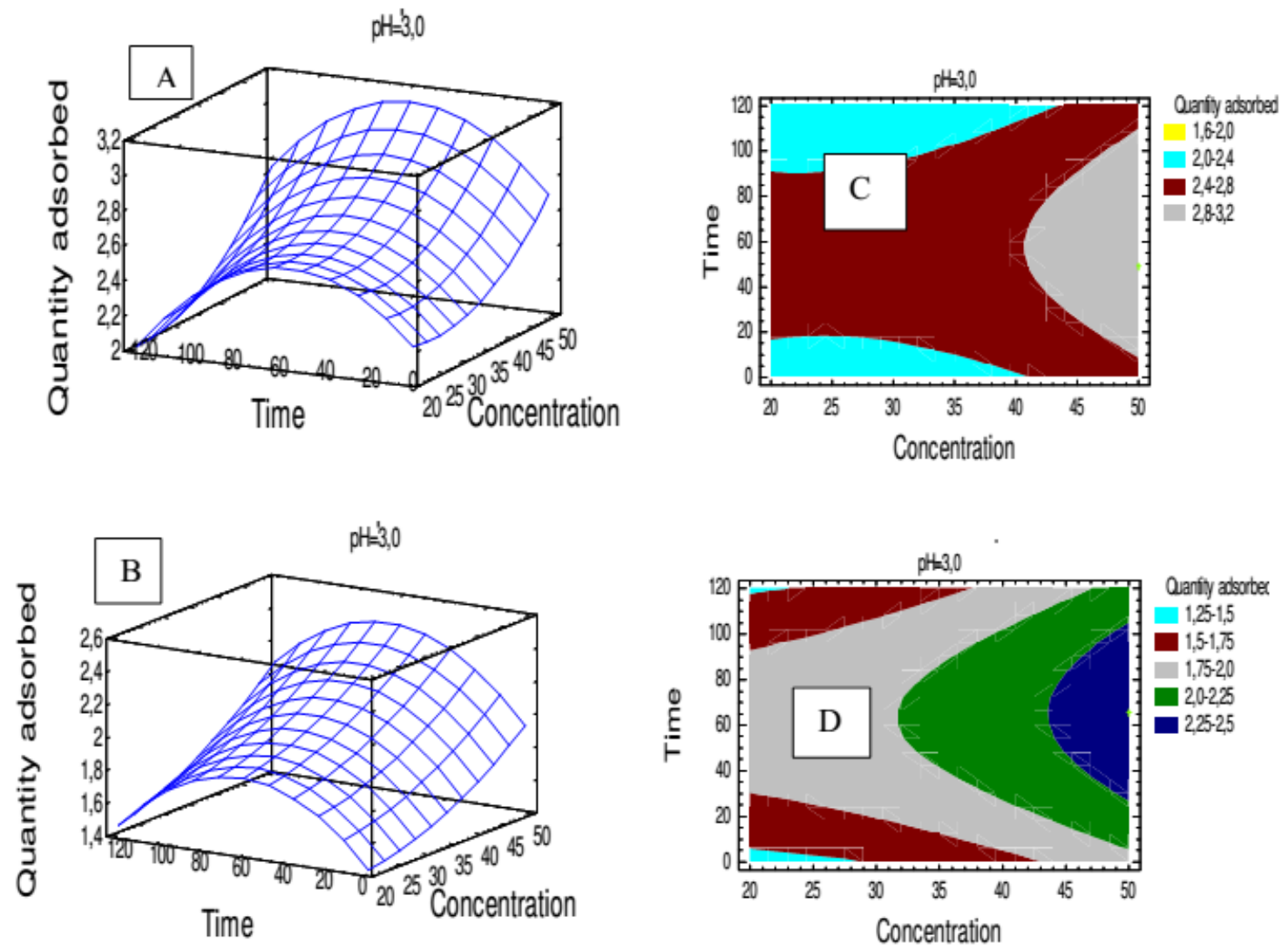

Fig.5. 3D response surface graph (A and B) and contour plot (C and D) of quantity adsorbed versus initial concentration $(\mathrm{mg} / \mathrm{L})$ and time $(\mathrm{min})$ onto PNAC and ASAC respectively at constant $\mathrm{Ph}$ 


\subsection{Process optimization}

The optimum conditions for the adsorption of 4-NA onto PNAC and ASAC were determined separately. The optimum values of the results of experiments under these optimum conditions are shown in table 5.

Table 5. Optimum values of process parameters for maximum adsorption capacity

\begin{tabular}{lllll}
\hline Optimum level & $\begin{array}{l}\text { Initial } \\
\text { concentration } \\
(\mathbf{m g} / \mathbf{L})\end{array}$ & $\mathbf{p H}$ & Contact time $(\mathbf{m i n})$ & $\begin{array}{l}\text { Quantity adsorbed } \\
(\mathbf{m g} / \mathbf{g})\end{array}$ \\
\hline PNAC & 50.0 & 3.0 & 49.0 & 3.10 \\
ASAC & 50.0 & 3.0 & 65.5 & 2.42 \\
\hline
\end{tabular}

The results obtained showed that peanut shell activated carbon exhibited a better performance than avocado seed activated carbon for the removal of 4-nitroaniline (4-NA) from aqueous media. This shows that PNAC is more effective in adsorbing 4-NA than ASAC which can be attributed to the higher microporosity, pore volume and large surface area of PNAC as well as to the different nature of the adsorbing surface.

\section{Conclusion}

In this study, peanut shells activated carbon and avocado seed activated carbon were investigated as possible adsorbents for 4-NA retention in aqueous solution. The optimum conditions for the removal of 4-NA from an aqueous solution by using PNAC and ASAC were successfully identified. RSM Central Composite design proved to be a useful technique for studying the effect of several factors on responses by varying them simultaneously and carrying out a limited number of experiments. It was shown that a second order polynomial regression model could properly interpret the experimental data with coefficients of determination (R2) values of $97.17 \%$ and $95.68 \%$ for PNAC and ASAC respectively. Results also showed that the optimum conditions for the adsorption of 4-NA from an aqueous solution onto PNAC and ASAC each of mass $25 \mathrm{mg}$ were as follows: the optimum initial 4-NA concentration of $50 \mathrm{mg} / \mathrm{L}$, $\mathrm{pH}$ of 3 and contact time of 49.0 minutes for PNAC and 65.5 minutes for ASAC were obtained using central composite design which resulted to an optimum adsorption capacity of $3.10 \mathrm{mg} / \mathrm{g}$ and $2.42 \mathrm{mg} / \mathrm{g}$ of 4-NA onto PNAC and ASAC respectively. High similarities were observed between the predicted and experimental results, which reflected the accuracy and applicability of the model.

\section{Acknowledgements}

We gratefully acknowledge the technical assistance rendered by the researchers of Material and Process Engineering Team (MPET)/RU-NOCHEE of the Department of Chemistry, Faculty of Science, University of Dschang, Cameroon and the World Academy of Sciences (TWAS), and Mr. DOUNGMO Giscard for his help on DRX analysis. 


\section{References}

Alemagi, D., Oben, M., Ertel, J., 2006. Mitigating industrial pollution along the Atlantic coast of Cameroon: An overview of Government Effort. The Environmentalist, 26(1), p. 41. Annadurai, G., Babu, S., Nagarajan, G., Ragu, K., 2000. Use of Box-Behnken design of experiments in the production of manganese peroxidase by Phancrochate chrysosporium (MTCC 767) and decolorization of crystal violet. Bioprocess Engineering, 23, p. 715.

Azeez, O., Adekola, A., 2016. Sorption of 4-NA on activated kaolinitic clay and Jatropha activated carbon in aqueous solution. Jordarn journal of chemistry, 11(2), p. 128.

Bhunia, F., Saha, N., Kaviraj, A., 2003. Effects of aniline-an aromatic amine to freshwater organisms. Ecotoxicology, 12, p. 397.

Dhiraj, S., Garima, M., 2008. Agricultural Waste Material as Potential Adsorbent for sequestering Heavy Metal Ions from Aqueous Solutions. A Review Saint longowal Institute of Engineering and Technology, Department of Chemistry,Longowal, India.

Ferrero, F. 2007. Dye removal by low cost adsorbent: Hazelnut shells in comparison with wood saw dust, Journal of Hazardous materials, 142, p. 144.

Gerald, B.m 2005. Nitro Compounds, Aromatics in Ullmann's Encyclopedia of Industrial Chemistry, 7th

Edition. Wiley, 2, p. 181.

Hui, T., Zaini, M., 2015. Potassium hydroxide activation of activated carbon: a commentary. Carbon Letters, 16(4), p. 275.

Khuri, A. I., 2017. Response surface methodology and its applications in agricultural and food sciences. Biomedical Biostatistics International Journal 5(5), p. 103.

Kifuani, K., Noki, V., Ndelo, D., Mukana, W., Ekoko, B., Ilinga, L., Mukinayi, J., 2012. Adosption de la quinine bichlorhydrate sûr un charbon actif peu couteux à base de la Bagasse de canne a sucre imprégnée de l'acide phosphorique. International Journal of Biological and Chemical Society, 6, p. 1337.

Kumar, A., 2013. Adsorptive removal of Rhodamine B (dye) using low cost adsorbents. Master Thesis. National Institute of Technology, Rourkela, India.

Lillo-Ródenas, M., Cazorla-Amorós, D., Linares-Solano, A., 2003. Understanding chemical reactions between carbons and $\mathrm{NaOH}$ and $\mathrm{KOH}$ : an insight into the chemical activation mechanism. Carbon, 41, p. 267.

Lopes-Ramon, M., Stoeckli, F., Moreno-Castilla, C., Carrasco-Marin, F., 1999. On the characterization of acidic and basic surface sites on carbons by various techniques. Carbon, 37, p. 1215.

Mackinson, F., Sticott, R., Partridge, L., 1981. Occupational Health Guidelines for Chemical Hazards. DHHS publication, Washington, D. C, USA, 3, p. 81.

Mckay, G., Prasad, G., Mouli, P., 1998. The removal ofdye colours from aqueous solutions by adsorption on low-cost materials. Water, Air and Soil pollution, 114, p. 423.

Montgomery, D., 2017. Design and Analysis of Experiments, 9thEdition. Wiley, New York, USA, p. 630.

Myers, R., Montgomery, D., Anderson-Cook, C., 2016. Response Surface Methodology: Process and product optimization using Designed experiment. John Wiley, Hoboken, New Jersey, USA,p. 856. 
Narayana, S., king, P., Gopinadh, R., Sreelakshmi, V., 2011. Response surface optimization of dye removal by using waste prawn shells. International journal of chemical sciences and Applications, 2(3), p. 186.

Ndi, N., Ketcha, M. J., Anagho, G., Ghogomu, N., Belibi, E., 2014. Physical and chemical characteristics of activated carbon prepared by pyrolysis of chemically treated Cola nut (cola acuminate) Shells wastes and its ability to adsorbed organics. International journal of Advanced Chemical Technology, 3, p. 1.

Omri, A., Benzina, M., 2012. Characterization of activated carbon prepared from a new raw lignocellulosic material: ziziphus spina- christi seeds. Tunisia Journal of Chemical society, 14, p. 175.

Oturan, M., Peiroten, J., Chartrin, P., Acher, A., 2000. Complete destruction of p-nitrophenol in aqueous medium by Electro- Fenton method. Environmental Science and Technology, 34, p. 3474. Ravikumar, K., Krishnan, S., Ramalingam, S., Balu, K., (2007). Optimization of process variables by the application of response surface methodology for dye removal using novel adsorbent. Dyes and Pigments, 72, p. 66.

Rhoda, H., Ideyonbe, O., 2015. Production of activated carbon and characterization from Snail Shell Waste (Helix pomatia). Advances in Chemical Engineering and Science, 5, p. 51.

Sadri, M., Alavi, M., Arami, M., 2010. Coagulation / flocculation process for dye removal using sludge from water treatment plant: Optimization through response surface methodology. Journal of Hazardous Materials, 175, p. 651.

Suarez-Garcia, F., Martinez-Alonso, A., Tascón, J., 2002. Pyrolysis of apple pulp: effect of operation conditions and chemical additives. Journal of Energy and Environmental Engineering, 3(32). 2251.

Tchuifon, D., Anagho, S., Njanja, E., Ghogomu, J., Ndifor-Angwafor, N., Kamgaing, T., (2014). Equilibrium and kenetic modelling of methyl orange adsorption from aqueous solution using rice husk and egussi peeling. International Journal of Chemical Science, 12, p. 141.

Veronica, C., 1999. One factor-at-a-time versus designed experiments. Journal of American Statistician, 53(2), p. 126-131.

Yagmur, E., Ozmak, M., Aktas, Z., 2008. A novel method for production of activated carbon from waste tea by chemical activation with microwave energy. Fuel, 87, p. 3278. 